\title{
Etiologic Agents of Bacterial Sepsis and Their Antibiotic Susceptibility Patterns among Patients Living with Human Immunodeficiency Virus at Gondar University Teaching Hospital, Northwest Ethiopia
}

\author{
Gelila Alebachew, ${ }^{1}$ Brhanu Teka, ${ }^{2}$ Mengistu Endris, \\ Yitayal Shiferaw, ${ }^{2,3}$ and Belay Tessema ${ }^{1}$ \\ ${ }^{1}$ Department of Medical Microbiology, School of Biomedical and Laboratory Sciences, \\ College of Medicine and Health Sciences, University of Gondar, Gondar, Ethiopia \\ ${ }^{2}$ Department of Microbiology, Immunology and Parasitology, Addis Ababa University, Addis Ababa, Ethiopia \\ ${ }^{3}$ Department of Medical Biotechnology, School of Medicine, Flinders University, Bedford Park, SA 5042, Australia \\ Correspondence should be addressed to Brhanu Teka; brhanu.teka@aau.edu.et
}

Received 30 December 2015; Revised 20 April 2016; Accepted 3 May 2016

Academic Editor: David A. Hildeman

Copyright (C) 2016 Gelila Alebachew et al. This is an open access article distributed under the Creative Commons Attribution License, which permits unrestricted use, distribution, and reproduction in any medium, provided the original work is properly cited.

Background. Bacterial sepsis is a major cause of illness in human immunodeficiency virus infected patients. There is scarce evidence about sepsis among HIV patients in Ethiopia. This study aimed to determine the etiologic agents of bacterial sepsis and their antibiotic susceptibility patterns among HIV infected patients. Methods. A cross-sectional study was carried out from March 1 to May 2, 2013. One hundred patients infected with HIV and suspected of having sepsis were included. Sociodemographic data were collected by interview and blood sample was aseptically collected from study participants. All blood cultures were incubated aerobically at $35^{\circ} \mathrm{C}$ and inspected daily for 7 days. The positive blood cultures were identified following the standard procedures and antimicrobial susceptibility testing was performed using disk diffusion technique. Data was entered by Epi-info version 3.5.1 and analysis was done using SPSS version 20. Results. Of the study participants, 31 (31\%) confirmed bacterial sepsis. The major isolates were 13 (13\%) Staphylococcus aureus, 8 (8\%) coagulates negative staphylococci, and 3 (3\%) viridans streptococci. Majority of the isolates, $25(80.6 \%)$, were multidrug resistant to two or more antimicrobial agents. Conclusions. Bacterial sepsis was a major cause of admission for HIV infected patients predominated by Staphylococcus aureus and coagulase negative staphylococci species and most of the isolates were multidrug resistant.

\section{Introduction}

Bacterial sepsis constitutes a significant public health problem and represents an important cause of morbidity and mortality in HIV/AIDS patients in the world. Epidemiologic studies have shown that $1 \%$ to $10 \%$ of the sepsis patients are individuals with HIV/AIDS in ICU [1]. Sepsis is systemic illness caused by microbial invasion of normally sterile parts of the body and commonly defined as the presence of infection with the systemic inflammatory response syndrome (SIRS); it is the presence of two or more of the following conditions: abnormal body temperature $\left(<36^{\circ} \mathrm{C}\left(96.8^{\circ} \mathrm{F}\right)\right.$ or $>38^{\circ} \mathrm{C}\left(100.4^{\circ} \mathrm{F}\right)$ ); heart rate $(>90$ beats $/ \mathrm{min})$; respiratory rate ( $>20$ breaths/min); and white blood cell (WBC) count $\left(<4000 / \mathrm{mm}^{3}\right.$ or $\left.>12,000 / \mathrm{mm}^{3}\right)$ [2].

The source of infection can be lung, genitourinary tract, gastrointestinal tract, skin or soft tissue, and so on [3]. Pathogenesis of bacteria due to the structural components of the Gram negative and Gram positive bacteria is responsible for initiating sepsis [4].

Sepsis can be caused by different types of bacteria. Gram negative bacteria are the most commonly isolated in septic 
patients and have lipopolysaccharide or endotoxin structure [5]. The percentage of patients with severe infections caused by Gram positive bacteria has increased in recent years, accounting for almost half of the incidents of septicemia and severe systemic infections [6,7]. Gram positive bacteria have no endotoxin, but they cause sepsis indistinguishable from Gram negative bacteria by two distinct mechanisms, by releasing exotoxins that act as super antigens (e.g., staphylococci or streptococci) and cell wall components of Gram positive bacteria (both peptidoglycan and lipoteichoic acid) [7].

The clinical syndrome is caused by microorganism and its virulence factors with the host and its inflammatory response. Bacteria with special relevance for sepsis include Gram positive: Streptococcus pneumonia, Streptococcus progenies, Streptococcus agalactiae, and Staphylococcus auras; and Gram negative: Neisseria meningitides, enteric (Escherichia coli, Klebsiella, Proteus, Enterobacter, Serratia, Citrobacter, and Salmonella), and nonenteric (Pseudomonas aeruginosa and Acinetobacter) [5].

People living with HIV are at greater risk for sepsis because of immune suppression. In areas of high HIV prevalence, sepsis might contribute substantially to overall mortality $[8,9]$.

Emerging of multidrug resistant bacteria can reduce the management of bacterial infections. Bacterial infection to the HIV infected cases can mostly be caused by the multidrug resistant organism. Multidrug resistant organism is a bacterium that is resistant to more than one antibiotic. If bacteria are resistant to an antibiotic, certain drug treatments will not work [10].

Like in many other developing countries, bacterial sepsis and antibiotic resistant organism in Ethiopia are the most common disease for mortality and morbidity. But there is no evidence for bacterial sepsis among HIV/AIDS patients and their interaction. Hence, this study aimed to analyze the etiologic agents of bacterial sepsis and susceptibility pattern of bacterial isolates among HIV infected patients.

\section{Materials and Methods}

2.1. Study Area. The study was conducted at University of Gondar Teaching Hospital which is located in Gondar town, Northwest Ethiopia, $737 \mathrm{~km}$ away from Addis Ababa. The University Hospital was purposefully selected with the fact that it is one of the biggest tertiary level referral and teaching hospitals in the region visited by about six million people from the surrounding zones and nearby regions both for inpatient and for outpatient treatment. The hospital consists of ART pharmacy, ART laboratory, ART clinic, ICU with 16 beds, 13 wards with 327 beds, and outpatient departments.

2.2. Study Design and Population. Hospital based crosssectional study was conducted among HIV/AIDS patients attending at ART clinic from March 1 to May 2, 2013.

2.3. Study Participants. All HIV/AIDS patients who were suspected of having sepsis and attended the University of
Gondar Teaching Hospital during the study period were enrolled in the study.

2.4. Inclusion Criteria. All confirmed HIV patients that were suspected of having sepsis by clinicians were included in the study.

2.5. Exclusion Criteria. Patients receiving antibiotic treatment and neonates were excluded from the study.

\subsection{Operational Definitions}

(i) Sepsis suspect is a patient who fulfils definition of SIRS.

(ii) SIRS is the presence of 2 or more of the following:

(a) Temperature $<36^{\circ} \mathrm{C}\left(96.8^{\circ} \mathrm{F}\right)$ (hypothermia) or $>38^{\circ} \mathrm{C}\left(100.4^{\circ} \mathrm{F}\right)$

(b) Heart rate $>90$ beats/min (tachycardia).

(c) Respiratory rate $>20$ breaths/min (tachypnea).

(d) WBC count $<4000 / \mathrm{mm}^{3}$ (leucopenia) or $>12,000 / \mathrm{mm}^{3}$ (leukocytosis).

2.7. Sample Size and Sampling Technique. During the twomonth study period, 100 study subjects were enrolled using convenient sampling technique from the study population visiting University of Gondar Teaching Hospital.

2.8. Data Collection and Laboratory Methods. A pretested, structured questionnaire was used to collect sociodemographic information, clinical signs, or symptoms by medical doctor. The pretest of the questionnaire was conducted in 10 patients at University of Gondar Teaching Hospital and pretest results were not included in the final results of the research but we used it to validate the questionnaire before conducting data collection.

2.8.1. Sample Collection and Handling. Blood samples were collected from patients before antibiotic therapy by using venipuncture technique. Careful skin cleaning using tincture of iodine and $70 \%$ alcohol was done before drawing blood to prevent contamination. Ten $\mathrm{mL}$ of blood sample from adults and $2 \mathrm{~mL}$ of blood sample from children were aseptically collected following the request of the clinician. Then, it was inoculated into a blood culture bottle each containing $45 \mathrm{~mL}$ of tryptone soy broth (TSB) (Oxoid) [11].

2.8.2. Culture and Identification. Blood cultures were incubated aerobically at $35^{\circ} \mathrm{C}$ and inspected daily for 7 days for the presence of visible microbial growth by observing any one of the following: turbidity, haemolysis, gas production, and coagulation of broth. For blood cultures that showed signs of microbial growth, subcultures were done onto blood, chocolate, and MacConkey agar (Oxoid). The blood and MacConkey agar plates were incubated in aerobic and chocolate agar in microaerophilic atmosphere using a candle jar at $35^{\circ} \mathrm{C}$ for 24-48 hours [11]. 
TABLE 1: Sociodemographic characteristics of HIV/AIDS patients suspected of having sepsis admitted to University of Gondar Teaching Hospital with their bacterial sepsis status, March 1, 2013, to May 2, 2013.

\begin{tabular}{|c|c|c|c|c|c|}
\hline \multirow{2}{*}{ Characteristics } & \multicolumn{2}{|c|}{ Confirmed bacterial sepsis } & \multirow{2}{*}{ Total number (\%) } & \multirow{2}{*}{$\chi^{2}$} & \multirow{2}{*}{$P$ value } \\
\hline & Yes number (\%) & No number (\%) & & & \\
\hline \multicolumn{6}{|l|}{ Sex } \\
\hline Male & $12(30.8)$ & $27(69.2)$ & $39(39)$ & \multirow{2}{*}{0.00} & \multirow{2}{*}{0.96} \\
\hline Female & $19(31.1)$ & $42(68.9)$ & $61(61)$ & & \\
\hline \multicolumn{6}{|l|}{ Age (years) } \\
\hline$<18$ & $2(33.3)$ & $4(66.7)$ & $6(6)$ & \multirow{2}{*}{0.02} & \multirow{2}{*}{0.99} \\
\hline $18+$ & $29(30.9)$ & $65(69.1)$ & $94(94)$ & & \\
\hline \multicolumn{6}{|l|}{ Residence } \\
\hline Urban & $16(36.4)$ & $28(63.6)$ & $44(44)$ & \multirow{2}{*}{1.06} & \multirow{2}{*}{0.30} \\
\hline Rural & $15(26.8)$ & $41(73.2)$ & $56(56)$ & & \\
\hline \multicolumn{6}{|l|}{ Educational status } \\
\hline Literate & $17(32.7)$ & $35(67.3)$ & $52(52)$ & \multirow{2}{*}{0.15} & \multirow{2}{*}{0.70} \\
\hline Illiterate & $14(29.2)$ & $34(70.8)$ & $48(48)$ & & \\
\hline \multicolumn{6}{|l|}{ Marital status } \\
\hline Single & $8(27.6)$ & $21(72.4)$ & $29(29)$ & \multirow{4}{*}{1.28} & \multirow{4}{*}{0.73} \\
\hline Married & $18(30.0)$ & $42(70.0)$ & $60(60)$ & & \\
\hline Divorced & $4(44.4)$ & $5(55.6)$ & $9(9)$ & & \\
\hline Widowed & $1(50.0)$ & $1(50.0)$ & $2(2)$ & & \\
\hline \multicolumn{6}{|l|}{ Occupation } \\
\hline Farmer & $5(29.4)$ & $12(70.6)$ & $17(17)$ & \multirow{9}{*}{2.49} & \multirow{9}{*}{0.96} \\
\hline House servant & $4(28.6)$ & $10(71.4)$ & $14(14)$ & & \\
\hline House wife & $5(23.8)$ & $16(76.2)$ & $21(21)$ & & \\
\hline Daily labor & $5(50.0)$ & $5(50.0)$ & $10(10)$ & & \\
\hline Merchant & $2(28.6)$ & $5(71.4)$ & $7(7)$ & & \\
\hline Employer (Gov't) & $5(35.7)$ & $9(64.3)$ & $14(14)$ & & \\
\hline Jobless & $3(30.3)$ & $7(70.0)$ & $10(10)$ & & \\
\hline Driver & $1(25.0)$ & $3(75.0)$ & $4(4)$ & & \\
\hline Others* & $1(33.3)$ & $2(66.7)$ & $3(3)$ & & \\
\hline Total & $31(31)$ & $69(69)$ & $100(100)$ & & \\
\hline
\end{tabular}

$*$ : builder, waiter, and working as hair stylist, $\chi^{2}=$ chi-squares.

All positive blood cultures were identified by their characteristic appearance on their respective media and Gram staining reaction and confirmed by the pattern of biochemical reactions using the standard method. Gram negative bacteria were identified by indole production, citrate utilization, motility, urease, oxidase, gas production, hydrogen sulfide production, carbohydrate fermentation, and lysine decarboxylases production tests. For Gram positive bacteria: for staphylococci, coagulase, catalase test, and manifold salt agar were done and, for streptococci, bacitracin and opt chin susceptibility tests were done. Blood culture broth which shows no microbial growth within 7 days was reported as culture negative, only after results were subcultured on blood, MacConkey, and chocolate agar [11].

2.8.3. Antimicrobial Susceptibility Testing. Antimicrobial susceptibility testing was performed for all isolates according to the criteria of the Clinical and Laboratory Standard Institute (CLSI) by disk diffusion method [12].

From a pure culture 3-5 selected colonies of bacteria were taken and transferred to a tube containing $5 \mathrm{~mL}$ of tryptone soy broth and mixed gently to a homogenous suspension and incubated at $35^{\circ} \mathrm{C}$ until the turbidity of the suspension becomes adjusted to a McFarland 0.5. A; sterile cotton swab was used and the excess suspension was removed by gentle rotation of the swab against the surface of the tube. The swab was then used to distribute the bacteria evenly over the entire surface of Mueller-Hinton agar (Oxoid) and for fastidious organisms' sensitivity was done on blood and chocolate agar plates [12].

The inoculated plates were left at room temperature to dry for 3-5 minutes and a set of 14 antibiotic discs (Oxoid) were placed $24 \mathrm{~mm}$ apart from each other on the surface of a Mueller-Hinton plate. Each disk was pressed down to ensure complete contact with the agar surface. The drugs for disc diffusion testing were in the following concentrations: ampicillin $(10 \mu \mathrm{g})$, amoxicillin-clavulanic acid $(30 \mu \mathrm{g})$, ceftriaxone $(30 \mu \mathrm{g})$, ciprofloxacin $(5 \mu \mathrm{g})$, chloramphenicol $(30 \mu \mathrm{g})$, sulfamethoxazole/trimethoprim $(25 \mu \mathrm{g})$, nitrofurantoin $(50 \mu \mathrm{g})$, erythromycin $(15 \mu \mathrm{g})$, gentamicin $(10 \mu \mathrm{g})$, methicillin $(5 \mu \mathrm{g})$, oxacillin $(1 \mu \mathrm{g})$, penicillin (10 IU), tetracycline $(30 \mu \mathrm{g})$, and vancomycin $(30 \mu \mathrm{g})$. Penicillin, vancomycin, erythromycin, 
oxacillin, and methicillin were tested only for Gram positive bacteria. The plates were then incubated at $35^{\circ} \mathrm{C}$ for $24-48$ hours. Diameters of the zone of inhibition around the disc were measured to the nearest millimeter using the ruler, and the isolates were classified as sensitive and resistant according to the standardized table supplied by the CLSI [12].

2.8.4. Quality Control. Standard reference strains of Escherichia coli (American Type Culture Collection- (ATCC-) 25922), Staphylococcus aureus (ATCC-25923), and Pseudomonas aeruginosa (ATCC-27853) were used as a quality control throughout the study for culture and antimicrobial susceptibility testing.

2.8.5. Data Analysis and Interpretation. Data entry was done by Epi-info version 3.5.1 and analysis was done using statistical package for social science (SPSS) software version 20. Descriptive statistical methods were employed to describe magnitude and percentage of sepsis. Chi-square and odds ratio tests with $95 \%$ confidence interval were used to determine presence and strength of association. In all cases $P$ value less than 0.05 was considered as statistically significant.

2.8.6. Ethical Consideration. This study was approved by the Research and Ethical Committee of the School of Biomedical and Laboratory Sciences, College of Medicine and Health Sciences, University of Gondar. Participation was voluntary and informed written consent was obtained from each study participant/guardian. The laboratory result was sent to physicians for appropriate treatment of the study participants. All information about the patients was kept confidential.

\section{Results}

One hundred HIV positive patients suspected of having sepsis were included in this study. Out of this, 39 (39\%) were males and $61(61 \%)$ were females. The age range of participants was $5-53$ years with mean and SD $33.2 \pm 9.8$. There was no significant association between the sociodemographic characteristics of participants and bacterial sepsis (Table 1).

Thirty-one isolates were obtained from blood samples of $31 \mathrm{HIV}$ infected patients suspected of having sepsis. Gram positive isolates were predominantly recovered from the blood cultures, that is, 26 (83.4\%) (Table 2). S. aureus 13 (42\%) was the leading bacterial isolate followed by coagulase negative staphylococci species 8 (25.8\%) in this study (Table 2). Five different Gram negative bacteria, namely, E. coli, $K$. ozaenae, $H$. influenzae, $P$. aeruginosa, and Serratia species, were also isolated from HIV infected patients. P. aeruginosa isolates were from a more extended ( 4 months) hospitalized child found in critical condition in the pediatrics ward.

3.1. Susceptibility Pattern of the Isolates. The antibiotic resistance patterns of the isolates to different antibiotics are described in Table 3. Ciprofloxacin, gentamicin, chloramphenicol, and oxacillin were active against $>75 \%$ of Gram positive organisms. Amoxicillin-clavulanic acid, ceftriaxone, nitrofurantoin, and vancomycin were active against $100 \%$ of
TABLE 2: Frequency of bacterial etiologies among HIV/AIDS patients in the University of Gondar Teaching Hospital from March 1, 2013, to May 2, 2013.

\begin{tabular}{lcc}
\hline Etiologic agent & Frequency & Percent \\
\hline Gram positive $((n=26(26 \%))$ & 13 & \\
$\quad$ S. aureus & 8 & 42 \\
CONS & 3 & 25.8 \\
Viridans streptococci & 2 & 9.7 \\
S. pyogenes & & 6.5 \\
Gram negative $((n=5)(5 \%))$ & 1 & \\
E. coli & 1 & 3.2 \\
K. ozaenae & 1 & 3.2 \\
H. influenzae & 1 & 3.2 \\
P. aeruginosa & 1 & 3.2 \\
Serratia species & 31 & 3.2 \\
\hline Total & & 100 \\
\hline
\end{tabular}

CONS: coagulase negative Staphylococcus.

Gram positive isolates. Ciprofloxacin and nitrofurantoin are active against $100 \%$ of Gram negative isolates (Table 3).

The most common isolates, $S$. aureus and CONS, were resistant mainly to ampicillin, methicillin, penicillin, and tetracycline. Five $S$. aureus isolates were resistant to methicillin while there was no vancomycin resistant $S$. aureus in this study (Table 3).

All Gram negative isolates (5 in number) were resistant to cotrimoxazole and most were resistant to ampicillin 4 (80\%), tetracycline $4(80 \%)$, amoxicillin-clavulanic acid $4(80 \%)$, and chloramphenicol $2(40 \%)$. The majority of Gram positive isolates 17 (65.3\%) were resistant to cotrimoxazole (Table 3).

All the five Gram negative isolates were also resistant to cotrimoxazole. The isolated $P$. aeruginosa was resistant to ampicillin, sulfamethoxazole, amoxicillin-clavulanic acid, ceftriaxone, gentamicin, tetracycline, and chloramphenicol except that of ciprofloxacin and nitrofurantoin (Table 3).

Majority of the isolates, 25 (80.6\%), were multidrug resistant, to two or more antimicrobial agents (Table 4). The antibiogram of the two common bacterial isolates $S$. aureus and CONS species was presented (Table 5).

\section{Discussion}

From this study, bacterial sepsis is one of the important public health problems among HIV/AIDS patients (31\%). But this frequency was lower than previous reports from China among surgically operated HIV/AIDS patients (41\%) [13] and Africa among HIV infected children (53\%) [14]. The magnitude difference might be due to the difference in the study participants in which most (94\%) were adults (Table 1). In addition, lesser magnitude of bacterial sepsis among HIV infected patients than surgically operated patients might also be explained by the susceptibility of the latter group for local bacterial infections that lead to bacterial sepsis.

In the present study, Gram positive sepsis (83.4\%) was more common than Gram negative sepsis (16.6\%) (Table 2). This may be due to the fact that the percentage of patients 


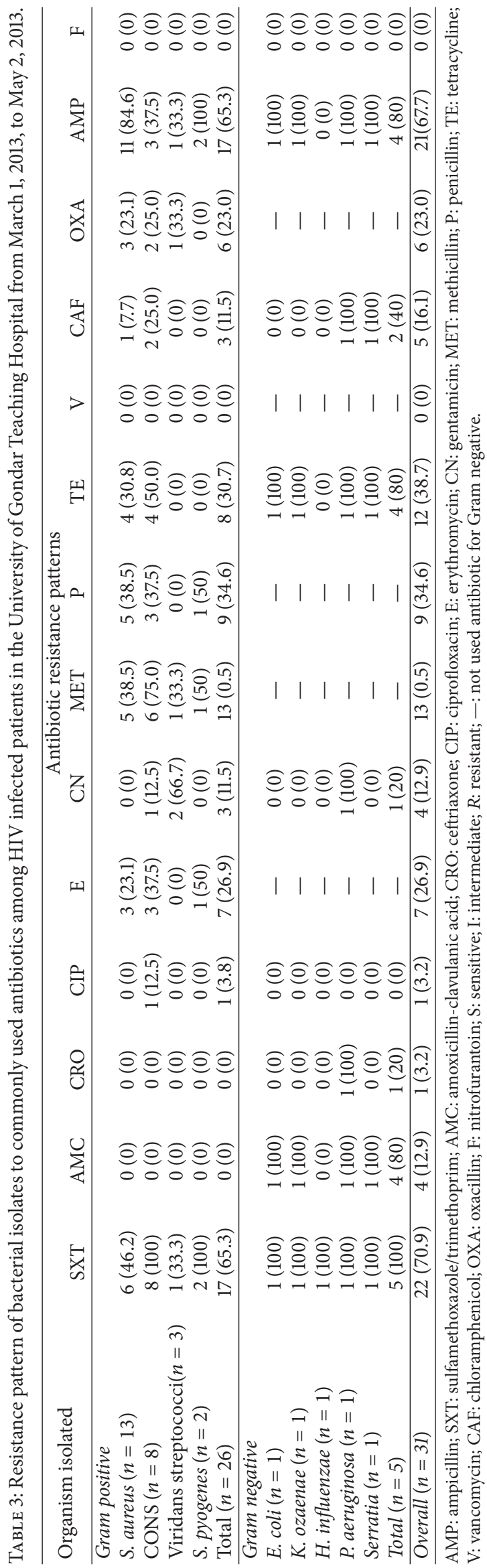


TABLE 4: Antibiotic resistance profile of bacterial isolate among HIV infected patients in the University of Gondar Teaching Hospital from March 1, 2013, to May 2, 2013.

\begin{tabular}{|c|c|c|c|c|c|c|}
\hline Bacterial isolate & $R_{0}(\%)$ & $R_{1}(\%)$ & $R_{2}(\%)$ & $R_{3}(\%)$ & $R_{4}(\%)$ & $R_{5}$ and above (\%) \\
\hline \multicolumn{7}{|l|}{ Gram positive } \\
\hline S. aureus $(n=13)$ & $1(7.6)$ & $1(7.6)$ & $5(38.4)$ & $2(15.3)$ & $1(7.6)$ & $3(23.0)$ \\
\hline CONS $(n=8)$ & $0(0)$ & $1(12.5)$ & $3(37.5)$ & $1(12.5)$ & $0(0)$ & $3(37.5)$ \\
\hline Viridans streptococci $(n=3)$ & $0(0)$ & $2(66.6)$ & $0(0)$ & $0(0)$ & $1(33.3)$ & $0(0)$ \\
\hline S. pyogenes $(n=2)$ & $0(0)$ & $0(0)$ & $0(0)$ & $1(50)$ & $0(0)$ & $1(50)$ \\
\hline Total (26) & $1(3.8)$ & $4(15.4)$ & $8(30.8)$ & $4(15.4)$ & $2(7.7)$ & $7(26.9)$ \\
\hline \multicolumn{7}{|l|}{ Gram negative } \\
\hline E. $\operatorname{coli}(n=1)$ & $0(0)$ & $0(0)$ & $0(0)$ & $0(0)$ & $1(100)$ & $0(0)$ \\
\hline K. ozaenae $(n=1)$ & $0(0)$ & $0(0)$ & $0(0)$ & $0(0)$ & $1(100)$ & $0(0)$ \\
\hline H. influenzae $(n=1)$ & $0(0)$ & $1(100)$ & $0(0)$ & $0(0)$ & $0(0)$ & $0(0)$ \\
\hline P. aeruginosa $(n=1)$ & $0(0)$ & $0(0)$ & $0(0)$ & $0(0)$ & $0(0)$ & $1(100)$ \\
\hline Serratia $(n=1)$ & $0(0)$ & $0(0)$ & $0(0)$ & $0(0)$ & $0(0)$ & $1(100)$ \\
\hline Total $(n=5)$ & $0(0)$ & $1(20)$ & $0(0)$ & $0(0)$ & $2(40)$ & $2(00)$ \\
\hline Overall $(n=31)$ & $1(3.2)$ & $5(16.1)$ & $8(25.8)$ & $4(12.9)$ & $4(12.9)$ & $9(29.0)$ \\
\hline
\end{tabular}

$R_{0}$ : nonresistant; $R_{1}$ : resistant for one antibiotic; $R_{2}$ : resistant for two antibiotics; $R_{3}$ : resistant for three antibiotics; $R_{4}$ : resistant for four antibiotics; $R_{5}$ and above: resistant for five and greater than five antibiotics.

TABLE 5: Multidrug resistance profile of frequently isolate bacteria among HIV infected patients in the University of Gondar Teaching Hospital from March 1, 2013, to May 2, 2013.

\begin{tabular}{|c|c|c|}
\hline Bacterial species & Antimicrobial agents & Number of resistant isolates (\%) \\
\hline \multirow{9}{*}{ S. aureus } & $\mathrm{AMP}$ and $\mathrm{P}$ & $2(15.3)$ \\
\hline & AMP and SXT & $2(15.3)$ \\
\hline & AMP and MET & $1(7.6)$ \\
\hline & AMP, MET, and OXA & $1(7.6)$ \\
\hline & AMP, SXT, and P & $1(7.6)$ \\
\hline & AMP, SXT, E, and TE & $1(7.6)$ \\
\hline & AMP, SXT, E, TE, and CAF & $1(7.6)$ \\
\hline & AMP, SXT, MET, TE, P, and OXA & $1(7.6)$ \\
\hline & AMP, P, E, TE, MET, and OXA & $1(7.6)$ \\
\hline \multirow{7}{*}{ CONS } & AMP and SXT & $1(12.5)$ \\
\hline & SXT and E & $1(12.5)$ \\
\hline & SXT and MET & $1(12.5)$ \\
\hline & SXT, MET, and E & $1(12.5)$ \\
\hline & SXT, MET, OXA, P, and TE & $1(12.5)$ \\
\hline & AMP, MET, CAF, CIP, E, P, SXT, and TE & $1(12.5)$ \\
\hline & AMP, MET, CAF, CN, E, OXA, P, SXT, and TE & $1(12.5)$ \\
\hline
\end{tabular}

AMP: ampicillin; SXT: sulfamethoxazole/trimethoprim; CIP: ciprofloxacin; E: erythromycin; CN: gentamicin; MET: methicillin; P: penicillin; TE: tetracycline; CAF: chloramphenicol; OXA: oxacillin; CONS: coagulase negative staphylococci.

with severe infections caused by Gram positive bacteria has increased in recent years, accounting for almost half of the incidents of septicemia and severe systemic infections $[6,7]$.

Of the $13 \mathrm{~S}$. aureus isolates, five (38.5\%) were MRSA. Methicillin resistant Staphylococcus aureus were also reported in different studies among HIV infected patients with the prevalence of $43.5 \%$ MRSA bacteraemia [15] and $10.3 \%$ had MRSA colonization [16]. These results showed that MRSA are the common isolates among HIV infected patients. The second most common isolates were CONS, 8 (25.8\%).
A similar study also reported that CONS are the major cause of bacterial infection in HIV/AIDS patients (58\%) [17].

The antibiotic susceptibility test results revealed that most isolates $22(70.9 \%)$ were resistant for most antibiotics tested. Gram positive and Gram negative isolates showed $65.3 \%$ and $100 \%$ resistance for cotrimoxazole, respectively (Table 3). The reason for this high resistant isolates among HIV/AIDS patients might be multifactorial. Inappropriate use of the antibiotic by patients might be one possible reason for the high resistance since cotrimoxazole has been given 
as prophylaxis for HIV/AIDS patients. This action might also enhance the resistance to the antimicrobial agent. It is also very difficult to generalize with this sample size about the cotrimoxazole resistance among isolates of HIV/AIDS patients. Large scale comparative study might answer the question. From previous retrospective cohort study among HIV infected patients, most of the isolates resist cotrimoxazole widespread use for prophylaxis may exacerbate antimicrobial resistance [14].

Gram positive bacteria also showed good sensitivity patterns to amoxicillin-clavulanic acid, ceftriaxone, nitrofurantoin, and vancomycin.

Gram negative bacteria showed good sensitivity pattern only for ciprofloxacin and nitrofurantoin (Table 3 ). This might be due to the use of this specific antibiotic which is not widespread.

One $P$. aeruginosa isolate was from a more extended (4 months) hospitalized child found in critical condition in the pediatrics ward. $P$. aeruginosa have also been more frequently recognized as nosocomial bacteraemia in HIV infected patients [17].

\section{Conclusions}

The prevalence of culture that confirmed bacterial sepsis among HIV infected patients was high in this study (31\%) and the two most common causative agents for bacterial sepsis are S. aureus and CONS. Amoxicillin-clavulanic acid, ceftriaxone, nitrofurantoin, and vancomycin were $100 \%$ active against Gram positive bacteria. Ciprofloxacin and nitrofurantoin were $100 \%$ active against Gram negative bacteria. Most of the isolates were multidrug resistant including cotrimoxazole.

\section{Recommendations}

Based on the findings of this study, we recommend that blood culture should be done for HIV infected patients suspected of having sepsis. Amoxicillin-clavulanic acid, ceftriaxone, nitrofurantoin, and vancomycin can be used against Gram positives if the laboratory setups are incomplete. Continuous antimicrobial susceptibility surveillance shall be implemented in the study area with large scale study among HIV/AIDS patients focusing on cotrimoxazole.

\section{Competing Interests}

The authors declare that they have no competing interests.

\section{Acknowledgments}

The authors acknowledge the Department of Medical Microbiology, University of Gondar, for allowing them reagents and materials during this study. The authors' special appreciation also goes to Mr. Aschalew Gelaw for his great contribution and guidance in the laboratory procedures of this study. Finally, the authors would like to thank all the study participants.

\section{References}

[1] D. C. Angus, W. T. Linde-Zwirble, J. Lidicker, G. Clermont, J. Carcillo, and M. R. Pinsky, "Epidemiology of severe sepsis in the United States: analysis of incidence, outcome, and associated costs of care," Critical Care Medicine, vol. 29, no. 7, pp. 1303-1310, 2001.

[2] A. Lever and I. Mackenzie, "Sepsis: definition, epidemiology, and diagnosis," The British Medical Journal, vol. 335, no. 7625, pp. 879-883, 2007.

[3] B. A. Cunha, "Sepsis and septic shock: selection of empiric antimicrobial therapy," Critical Care Clinics, vol. 24, no. 2, pp. 313-334, 2008.

[4] E. Jean-Baptiste, "Cellular mechanisms in sepsis," Journal of Intensive Care Medicine, vol. 22, no. 2, pp. 63-72, 2007.

[5] S. Latif, M. S. Anwar, and I. Ahmad, "Bacterial pathogens responsible for blood stream infection and pattern of drug resistance in a tertiary care hospital of Lahore," Biomedica, vol. 25, pp. 101-105, 2009.

[6] T. van der Poll and S. M. Opal, "Host-pathogen interactions in sepsis," The Lancet Infectious Diseases, vol. 8, no. 1, pp. 32-43, 2008.

[7] D. Sun, B. Raisley, M. Langer et al., "Anti-peptidoglycan antibodies and $F_{c} \gamma$ receptors are the key mediators of inflammation in gram-positive sepsis," Journal of Immunology, vol. 189, no. 5, pp. 2423-2431, 2012.

[8] A. C. Cheng, T. E. West, D. Limmathurotsakul, and S. J. Peacock, "Strategies to reduce mortality from bacterial sepsis in adults in developing countries," PLoS Medicine, vol. 5, no. 8, article e175, 2008.

[9] A. Bane, A. G. Yohannes, and D. Fekade, "Morbidity and mortality of adult patients with HIV/AIDS at Tikur Anbessa Teaching Hospital, Addis Ababa, Ethiopia," Ethiopian Medical Journal, vol. 41, no. 2, pp. 131-140, 2003.

[10] K. D. Waikhom and K. S. Devi, "Emergence of multidrug resistant bacterial infection in HIV/AIDS cases," The Health, vol. 3, pp. 49-52, 2012.

[11] Clinical and Laboratory Standard Institution, "Principles and procedures for blood culture; approved guideline," Clinical and Laboratory Standard Institution Document M47-A, Clinical and Laboratory Standard Institution, Wayne, Pa, USA, 2007.

[12] Clinical and Laboratory Standards Institute, Performance Standards for Antimicrobial Disk Susceptibility Tests, Clinical and Laboratory Standards Institute Document M2-A9, Clinical and Laboratory Standards Institute, Wayne, Pa, USA, 9th edition, 2006.

[13] B. Liu, L. Zhang, R. Guo, J. Su, L. Li, and Y. Si, "Antiinfective treatment in HIV-infected patients during perioperative period," AIDS Research and Therapy, vol. 9, article 36, 2012.

[14] H. B. Jaspan, L. C. Huang, M. F. Cotton, A. Whitelaw, and L. Myer, "Bacterial disease and antimicrobial susceptibility patterns in HIV-infected, hospitalized children: a retrospective cohort study," PLoS ONE, vol. 3, no. 9, article e3260, 2008.

[15] M. D. Burkey, L. E. Wilson, R. D. Moore, G. M. Lucas, J. Francis, and K. A. Gebo, "The incidence of and risk factors for MRSA bacteraemia in an HIV-infected cohort in the HAART era," HIV Medicine, vol. 9, no. 10, pp. 858-862, 2008.

[16] M. J. Cenizal, R. D. Hardy, M. Anderson, K. Katz, and D. J. Skiest, "Prevalence of and risk factors for methicillin-resistant 
Staphylococcus aureus (MRSA) nasal colonization in HIVinfected ambulatory patients," Journal of Acquired Immune Deficiency Syndromes, vol. 48, no. 5, pp. 567-571, 2008.

[17] A. I. Adeyemi, A. A. Sulaiman, B. B. Solomon, O. A. Chinedu, and I. A. Victor, "Bacterial bloodstream infections in HIVinfected adults attending a lagos teaching hospital," Journal of Health, Population and Nutrition, vol. 28, no. 4, pp. 318-326, 2010. 

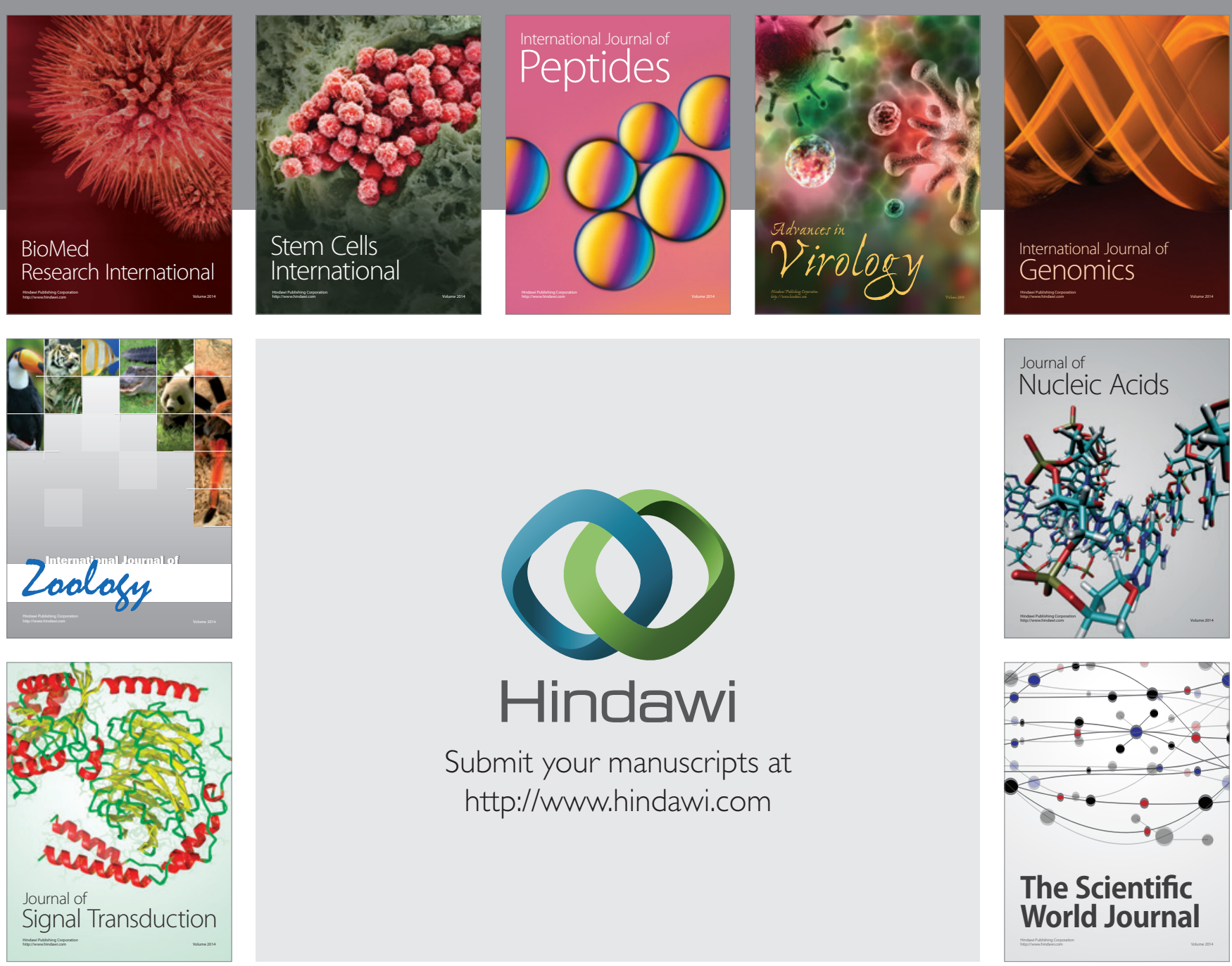

Submit your manuscripts at

http://www.hindawi.com
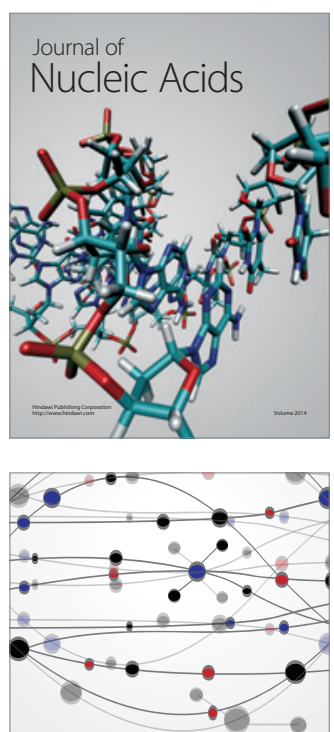

The Scientific World Journal
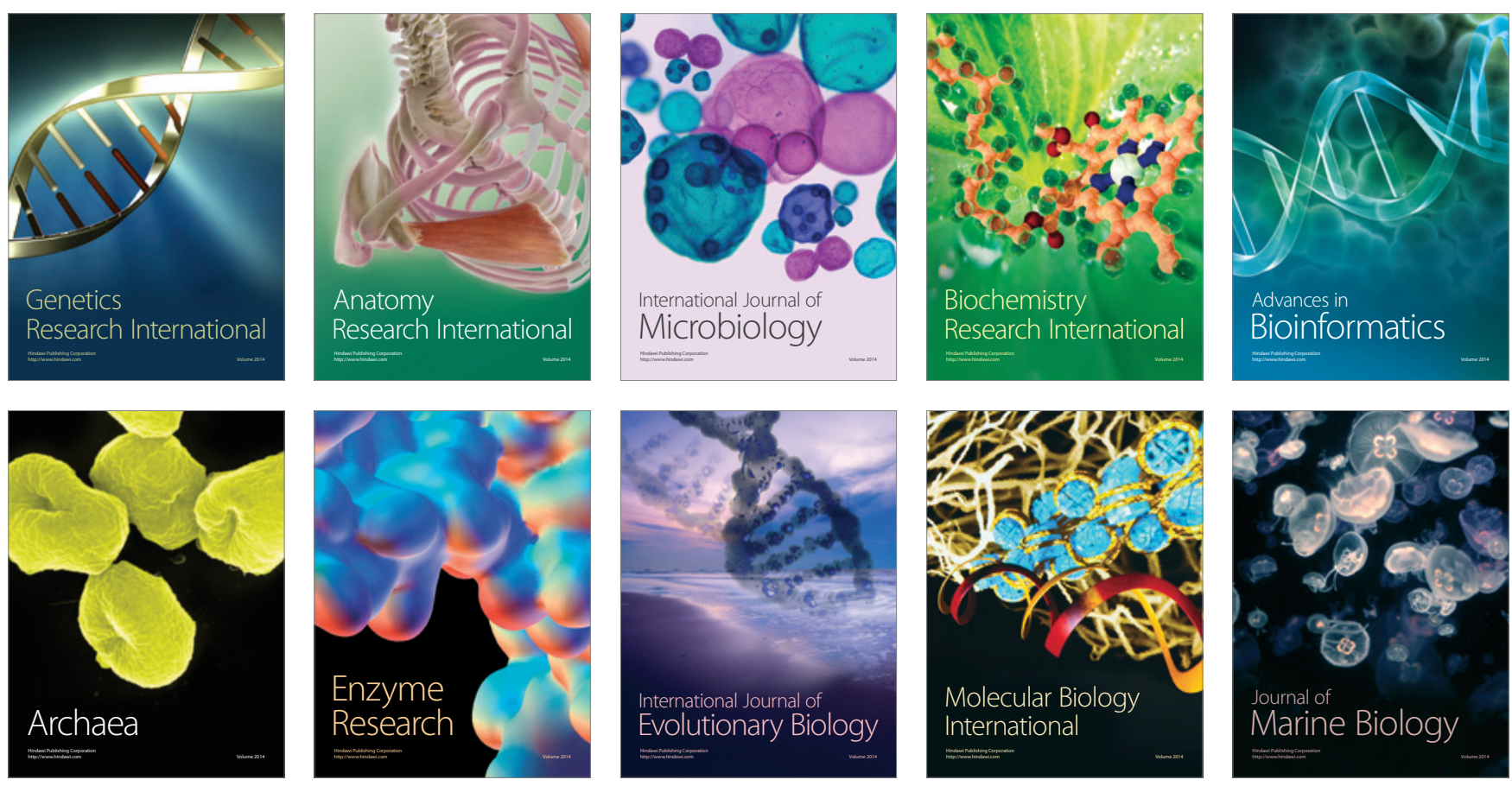